Artigo de revisão

\title{
CONCEPÇÕES METODOLÓGICAS PARA O ENSINO DO BASQUETEBOL.
}

$O$ ensino do basquetebol

\author{
${ }^{1}$ Williams André de Almeida Vanderlei Filho
}

\begin{abstract}
RESUMO
Introdução: O esporte é tido como um fenômeno sociocultural, fenômeno esse que com o passar dos anos vem ganhando mais visibilidade e mais adeptos de sua prática em todo o mundo, é na Grécia Antigo é onde se tem os primeiros registros da prática esportiva de forma organizada. Dentro do esporte, existem os esportes coletivos, onde esses são praticados em forma de jogo e requer a participação de duas ou mais pessoas contra uma equipe adversária, podendo ser também chamado de esporte em grupo ou em equipe e necessita da utilização de um determinado objeto como bola, disco, bola ovoide, etc. Inserido nos esportes coletivos se tem a modalidade esportiva do Basquetebol, criada no ano de 1891 pelo professor de Educação Física do Springfield College James Naismith. Essa modalidade se apresenta como um esporte coletivo de invasão, oposição e cooperação cujo objetivo é a realização da cesta. Objetivo: O presente trabalho teve como objetivo identificar os mais variados métodos de ensino/aprendizagem/treinamento aplicados ao Basquetebol. Método: O referido estudo tratase de uma revisão de literatura de natureza qualitativa, e descritiva onde foram utilizados artigos e livros (2007 - 2018) disponíveis nas bases de dados do: SciELO, PubMed, Bireme e Google Scholar. Resultados e Discussão: Foram encontradas metodologias de ensino tradicionais (Global, Parcial e Misto) e metodologias de ensino contemporâneas (Iniciação Esportiva Universal, Jogos Desportivos Coletivos, TGfU e Situacional). Conclusão: Diante dos achados, pode-se concluir que a utilização das metodologias irá depender de uma série de fatores, seja o ambiente trabalho (escola, iniciação esportiva ou treinamento) ou por conta das experiências do treinador ou professor de Educação Física.
\end{abstract}

Palavras-chave: Esporte, Métodos de Ensino, Basquetebol.

\section{METHODOLOGICAL CONCEPTIONS FOR THE TEACHING OF BASKETBALL.}

\section{ABSTRACT}

\section{The Teaching of Basketball}

Introduction: The sport is considered as a sociocultural phenomenon, a phenomenon that over the years has been gaining more visibility and more adherents of its practice around the world, it is in Ancient Greece that is where one has the first records of the sport practice of form organized. Within the sport, there are collective sports, where these are practiced in game form and requires the participation of two or more people against an opposing team, and may also be called team or team sports and requires the use of a certain object such as ball, disc, ovoid ball, etc. Inserted in the collective sports has the sport modality of the Basketball, created in the year of 1891 by the professor of Physical Education of Springfield College James Naismith. This modality presents itself as a collective sport of invasion, opposition and cooperation whose objective is the realization of the basket. Objective: This study aimed to identify the most varied teaching / learning / training methods applied to Basketball. Methodology: This study is a qualitative and descriptive literature review where articles and books (2007 - 2018) were used in the databases of: SciELO, PubMed, Bireme and Google Scholar. Results and Discussion: Traditional teaching methodologies (Global, Partial and Mixed) and contemporary teaching methodologies (Universal Sports Initiation, Collective Sports Games, TGfU and Situational) were found. Conclusion: In the face of the findings, it can be concluded that the use of methodologies will depend on a series of factors, whether the work environment (school, sports initiation or training) or the experiences of the coach or teacher of Physical Education.

Key words: Sport, Teaching Methods, Basketball. 


\section{INTRODUÇ̃̃O}

O esporte é tido como um fenômeno sociocultural e que com o passar dos tempos, a prática esportiva vem crescendo em todo mundo. Prática essa que pode ser realizada de forma coletiva ou individual para fins competitivos, para saúde ou simplesmente para fins de recreação (TUBINO, 2010).

A palavra "sport" foi utilizada pela primeira vez na Grã-Bretanha no século $X V$ porém é apenas entre o século XVIII e XIX que foi utilizada com o sentido que é conhecida atualmente. Ainda não se sabe ao certo quando aconteceu 0 surgimento do esporte de forma exata, mas várias evidências mostram que na antiguidade existiam atividades físicas que eram realizadas como forma de sobrevivência (caça, natação, corridas, etc.), ou seja, como forma de necessidade. Com o passar dos séculos, na Grécia antiga, começaram a utilizar o exercício como forma educativa e posteriormente aconteceram os primeiros Jogos Gregos, onde tevese o primeiro registro organizacional para uma competição. Nos jogos Olímpicos da Grécia antiga foram observados os primeiros registros de periodização para o treinamento dos atletas daquela época (TUBINO, 2010).

Chegando à modernidade, mais precisamente no século $\mathrm{XIX}$, O diretor do Rugby College chamado Thomas Arnold teve a ideia de fazer com que os jogos já existentes tivessem pequenas competições e assim começaram a surgir os primeiros clubes esportivos. $\mathrm{O}$ criador dos jogos olímpicos, o senhor Pierre de Coubertin no ano de 1982 notou que o esporte poderia ser um grande aliado contra conflitos entre as nações daquela época, quatro anos mais tarde na Grécia, mais precisamente em Atenas no ano de 1896 iniciaram-se novamente os Jogos Olímpicos da era moderna tendo como base os jogos da Grécia antiga e assim fazendo com que o Esporte fosse impulsionado novamente (TUBINO, 2010).

No final da década de 70 , a UNESCO ficou responsável pela elaboração de um documento; esse denominado Carta Internacional da Educação Física e do Esporte que reconhece que essa prática passa a ser direito de todas as pessoas independente de idade, sexo ou de 
suas condições físicas (TUBINO, 2010).

Sendo assim, partindo para um ponto mais específico, os esportes coletivos possuem como algumas características próprias: são praticados em forma de jogo, jogo esse que requer a participação de duas ou mais pessoas contra uma equipe adversária, podendo também ser chamado de Esporte em grupo ou em equipe e requer a utilização de um determinado objeto como bola, disco, etc. (MENEZES, 2012).

Para o ensino dos esportes coletivos, existem metodologias de ensino que que visam alcançar determinados objetivos como por exemplo melhora da técnica em determinada modalidade esportiva, criando situações particulares de jogo com crescente complexidade para que posteriormente seja obtido o êxito quando se estiver em situação real de jogo. Existem métodos de ensino tradicionais (Parcial, Global e Misto) e métodos de ensino contemporâneos (Iniciação Esportiva Universal, Jogos Desportivos Coletivos, Situacional e TGFU) (GALATTI et al., 2012).
A modalidade esportiva coletiva utilizada para realização do presente trabalho foi o Basquete. Essa modalidade se apresenta como um esporte coletivo de oposição e cooperação que nasceu no ano de 1891 quando o professor de Educação Física James Naismith do Springfield College, colégio internacional da Associação Cristã de Moços (ACM), recebeu a difícil tarefa de criar um esporte que fosse possível a prática do mesmo por seus alunos em um local fechado por conta do rigoroso inverno que afligia a cidade de Massachusetts naquele mesmo ano, o que impedia a prática das aulas de Educação Física e dos esportes populares na época que era o Beisebol e principalmente naquela região predominava o Futebol Americano (OLIVEIRA, 2012).

Naquela época, James queria propor um esporte em que não houvesse contato físico ou que usasse os pés para que não viesse a se tornar muito violento por conta da cultura do Futebol Americano que predominava no local, assim, teve a ideia de pendurar duas cestas de pêssegos em um local fixo a uma altura no qual ele julgou adequada, cerca de 3,05 metros 
(altura que se mantem até os dias atuais) assim gerando certo grau de dificuldade e imaginando que nenhum jogador da defesa seria capaz de interceptar a bola, James também foi o autor das primeiras regras do esporte contendo 13 itens, deste modo, nascendo 0 esporte chamado de Basquetebol (Basketball, palavra em inglês com o significado de bola-ao-cesto) e posteriormente tornando-se um dos esportes mais populares do mundo (OLIVEIRA, 2012).

Pode-se dizer que o Brasil foi um dos primeiros países da América do Sul a conhecer o esporte basquete... Dando continuidade a história desse esporte, um professor de Artes chamado Augusto Shaw que havia recebido um convite para lecionar no Mackenzie College em São Paulo, trazendo consigo alguns livros e junto com esses havia uma bola de Basquetebol, porém o esporte não foi bem recebido no Brasil pelos homens, porque foi imediatamente aprovada por mulheres, mas Augusto Shaw após várias conversas com seus alunos foi conseguindo aos poucos mostrar que o esporte poderia ser praticado tanto por homens quanto por mulheres sem nenhum problema (OLIVEIRA, 2012).

$A$ aceitação de fato se deu por conta do professor Oscar Thompson e Henry J. Sims, este último era o diretor de Educação Física da ACM (Associação Cristã de Moços) e no ano de 1912 aconteceram às primeiras partidas de Basquetebol no Brasil entre a ACM e o Mackenzie College de São Paulo (OLIVEIRA, 2012).

Com o passar dos anos e com a evolução do Basquetebol, fica evidente que o aspecto mais relevante para a formação dos atletas da modalidade é o aspecto motor e dentro de todo o processo de ensino aprendizagem e treinamento, o treinador sempre deve procurar melhorias nos métodos de ensino das habilidades (técnica e tática) do Basquetebol sempre tendo em vista aperfeiçoar as capacidades já existentes (GALATTI et al., 2012). Sendo assim, o objetivo do referido estudo foi identificar os mais variados métodos de ensino aplicados ao ensino do basquete.

\section{MÉTODO}

$O$ referido estudo trata-se de uma revisão de literatura que visa 
gerar novos conhecimentos sobre temas já abordados, pois, trata-se de uma pesquisa qualitativa, de natureza descritiva em que foram utilizados artigos e livros disponíveis nas seguintes bases de dados: SciELO, PubMed, Bireme e Google Scholar sobre o tema abordado.

Como critério de inclusão foram utilizados artigos científicos e livros coletados nas bases de dados a partir do ano de 2007 até os dias atuais. Como critério de exclusão foram descartados artigos científicos que fugiam da realidade do tema abordado, anteriores ao ano de 2007; e foram utilizados os seguintes termos de indexação: Esporte, Métodos de Ensino, Basquetebol, Aprendizagem.

\section{RESULTADOS E DISCUSSÃO}

A partir dos estudos (resultados) encontrados para este estudo, neste momento, irá se abordar os mesmos métodos de ensino descritos acima, só que desta feita em forma de discussão, mostrando a expertise dos autores em relação ao esporte coletivo e especificamente sobre o ensino do basquete.

Segundo De Rose e colaboradores (2009), na atualidade o esporte de forma geral vem ganhando cada vez mais, um grande número de praticantes e passando a fazer parte da vida de muitas pessoas, seja como forma de lazer, para grupos especiais, até $\mathrm{o}$ alto rendimento. $\mathrm{O}$ basquete mais precisamente com o passar dos anos passou por diversas mudanças desde a sua criação em 1891. Os avanços tecnológicos propiciaram uma melhor compreensão do esporte e também a busca por novas metodologias de ensino/aprendizagem que favoreçam 0 entendimento da modalidade esportiva, respeitando sempre as individualidades dos alunos/atletas sempre procurando diversificar os movimentos para que se tenha uma maior facilidade de acesso ao esporte propriamente dito.

Para que seja possível a utilização de uma determinada metodologia de ensino, primeiro se deve ter em mente a lógica tática e técnica da modalidade esportiva que irá ser trabalhada (Basquetebol). Quando se parte para a técnica, segundo De Rose e colaboradores (2009) deve ser levado em consideração alguns fundamentos como: aprender a 
dominar o corpo, controlar a bola, passe, recepção, drible e finalização (arremesso e realização da cesta).

No que diz respeito a aspectos táticos, pode-se resumir em sistemas ofensivos e defensivos, onde a ligação entre esses dois sistemas é denominado de transição que é onde se tem a posse de bola e a perda da mesma, criando assim situações-problema para que posteriormente seja possível entender a lógica do jogo. De Rose e colaboradores (2009) não só defende que na iniciação os jogos devem ter um caráter lúdico, mas que esses jogos também devem favorecer com que os alunos e atletas compreendam a lógica entre a tática e a técnica dos jogos esportivos coletivos.

Partindo para as metodologias de ensino que podem ser utilizadas durante o processo de ensino/aprendizagem/treinamento de atletas e alunos, Coutinho (2009) comenta que o ensino dos esportes coletivos teve unicamente como base por muitos anos o método parcial (também chamado de método analítico), esse método consiste em fracionar as partes do esporte propriamente dito, para que essas frações cheguem até o jogo regular. Tal método teve como base principal, o treinamento esportivo limitando-se muitas vezes apenas a progressão técnica o que deixava 0 treino monótono.

O que foi descrito anteriormente corrobora com os achados de Tolves e colaboradores (2014), onde se utilizou exclusivamente 0 método parcial para as aulas de Educação Física e constatou-se que, a maioria dos alunos se mostrou desmotivados e por muitas vezes ocorrendo dispersão dos mesmos, pois não ocorria a prática do jogo e só eram realizados fundamentos de forma isolada para que ao final da aula fosse realizado o jogo formal. Mesmo com a melhora dos aspectos técnicos por parte de alguns alunos e outros que possuíam uma melhor desenvoltura com a técnica faziam as aulas como forma de aprimoramento, ainda assim, o ambiente tornava-se monótono.

Já no método Global, sua principal característica é a criação de jogos que variam de acordo com a faixa etária, aumentando gradativamente as dificuldades até chegar o jogo regular (jogo formal), ou seja, o aluno ou atleta em 
iniciação vai aprender as características do jogo, jogando desde o primeiro momento a partir de jogos adaptados (jogos, com poucas alterações nas regras).

Segundo Damasceno e Teixeira (2011) o método Global se mostra de melhor aplicabilidade em comparação ao método parcial, pois como foi dito no parágrafo anterior, o jogo é realizado desde o primeiro contato, assim, mantendo os alunos e atletas mais motivados para a prática esportiva, pois a tática e técnica permanecem sempre juntas. Por outro lado a progressão técnica é realizada de forma mais lenta, pois na utilização desse método não permite correções individuais.

Ainda Damasceno e Teixeira (2011), observaram através de uma pesquisa de campo, em que quatro treinadores de Futsal que foram entrevistados fazem quase que exclusivamente o uso do método Global, pois, mesmo sendo difícil de compreender por parte de alguns jogadores, tal método tornou-se eficaz por desenvolver a inteligência tática dos mesmos.

Tolves e colaboradores (2014) utilizaram do método Global de ensino durante quatro semanas nas aulas de Educação Física por meio de jogos adaptados (jogos esses que possuem algumas adaptações nas regras) até o jogo formal, com o intuito de desenvolver a técnica dentro do jogo propriamente dito. Perceberam que os alunos se mantinham motivados durante toda a aula e participando sempre de forma ativa, fazendo que eles compreendessem os aspectos técnicos e táticos da modalidade Futsal.

Contudo, foi constatado que teve certa demora no progresso técnico por parte dos alunos, principalmente daqueles alunos que possuíam um nível de habilidade inferior, porque tal método não permitia fazer correções de forma mais individualizada.

Ambrust e colaboradores (2010) compararam a utilização dos métodos Parcial e Global para aprendizagem de um gesto técnico, foi constatado que não houve diferença significativa entre os métodos, porém, na utilização do método Global os atletas se mostraram mais interessados $\mathrm{e}$ mais motivados em comparação aos atletas treinados com o método parcial, corroborando o que foi dito nos parágrafos anteriores. 
Já para o método misto, neste ocorre a junção do método Parcial com o método Global; conforme Romão e colaboradores (2017) esse método pode ser aplicado com exercícios que ensine um determinado gesto técnico de forma fragmentada (exemplo: arremesso no basquete), para que ao final da atividade os fragmentos formem o gesto como um todo, aumentando a dificuldade de forma gradativa. Esse método oferece 0 aprendizado de forma mais completa, pois, faz com que o atleta aprenda o gesto aos poucos para que posteriormente seja realizado o jogo formal.

Casagrande (2012) afirma que, tal método oferece vantagens em relação aos métodos que foram citados anteriormente, pois une atividades que irão promover melhorias nos gestos técnicos e posteriormente realização do jogo formal, o que irá proporcionar uma maior motivação por parte dos atletas. Acredita-se que, a prevalência desse método é bem evidente nos dias atuais, tanto em clubes esportivos quanto nas aulas de Educação Física das escolas.

Casagrande (2012) também constatou que, durante os treinos e aulas de Educação Física, o professor divide a aula em três períodos: dois são realizados atividades com a metodologia parcial e outro com a metodologia global. Na parte em que é utilizado o método parcial, se dá uma ênfase nos fundamentos técnicos específicos daquela modalidade esportiva que irá ser trabalhada, para que posteriormente seja realizado o jogo formal. Nas turmas de iniciação, o jogo formal tem caráter mais lúdico enquanto nas turmas mais avançadas é trabalhada a parte tática.

A proposta metodológica da Iniciação Esportiva Universal (IEU) é fazer com que os atletas e alunos possam desenvolver de forma paralela tanto a aprendizagem tática quanto a aprendizagem motora. Segundo Romão e colaboradores (2017), tal metodologia tem a proposta de recuperar os jogos de rua, fazendo com que a criança compreenda 0 jogo de forma incidental, realizando atividades com ou sem bola, mas sempre relacionando com a modalidade esportiva coletiva que irá ser trabalhada.

Casagrande (2012) diz que na Iniciação Esportiva Universal 
deve-se dar um destaque maior para que a criança jogue e brinque em diversos ambientes, seja na rua, minicampos de terra batida, ou em qualquer outro espaço livre, ou seja, dê uma ênfase maior ao lúdico. A realização de jogos nesses ambientes vem se tornando cada vez mais difícil de serem vistas nos dias atuais. Nessa metodologia a aprendizagem se dá através da aprendizagem incidental e a intencional, onde inicialmente se jogava para aprender, através de jogos populares o movimento era construído de forma incidental. Em seguida, após a construção do movimento era que se tinha 0 propósito de aprender, isto é, aprender jogando.

Leão e colaboradores (2011) comentam que, tal proposta metodológica leva em consideração o desenvolvimento do conhecimento tático declarativo que se trata de "o que fazer", juntamente com o conhecimento tático processual que se trata de "como fazer", fazendo a utilização de diversos jogos que pregam diferentes meios de utilização da tática. Utilizando jogos simples sem oposição para que posteriormente sejam realizadas atividades com 1, 2 e até 3 elementos didáticos com a utilização de oposição, sendo esta realizada de forma simplificada. Jogos adaptados são realizados com igualdade ou superioridade numérica, assim, criando um contexto similar ao jogo formal.

Sabe-se que a metodologia TGFU (Teaching Games for Understanding) se baseia basicamente pela realização de jogos reduzidos na iniciação esportiva, jogos esses que irão contribuir com o entendimento da tática do jogo formal. Segundo Bolonhini (2009), a criação dessa metodologia de ensino nos anos 80 se deu por conta das aulas e treinos se desassociavam do jogo formal e só visavam 0 ensino das habilidades técnicas, com isso, gerando um baixo interesse pelas aulas por parte dos alunos e atletas.

Para que se tenha um maior entrosamento por parte dos alunos e atletas, deve-se ter um maior número de atividades a serem desenvolvidas, atividades essas que devem ser variadas, pois farão com que as crianças se sintam mais motivadas para realiza-las, 0 professor/treinador possui um papel fundamental por criar essas atividades envolvendo situações- 
problema e fazer com que os alunos busquem as mais variadas respostas para resolução das mesmas. Com o passar dos treinos ou aulas, o nível de complexidade das atividades propostas deve ser aumentado para que os atletas desenvolvam uma melhor compreensão do jogo.

No TGFU, as habilidades técnicas dos atletas irão surgir em função da tática, ou seja, dentro do contexto do jogo onde o treino deixa de ser monótono e mecanizado para ser um treino mais dinâmico e com atividades variadas. Perceber 0 jogo na metodologia TGFU é de suma importância, pois é o onde o atleta irá interpretar as informações oriundas do ambiente do jogo e procurar a melhor forma de solucionar determinado problema ("o que fazer" e "como fazer"). É de grande importância que os jogos reduzidos tenha a dificuldade sendo aumentada de forma gradativa, se aproximando cada vez mais do jogo formal partindo de dois pilares: estratégia e tática ou técnicas e habilidades.

Segundo Costa e colaboradores (2010), o TGFU recomenda que os jogos de iniciação sejam definidos por sua característica (exemplo: basquete = jogo de invasão), para que em seguida fossem propostas atividades envolvendo situaçõesproblema dentro dos jogos reduzidos. Tais atividades irão fazer com que os alunos e atletas se sintam mais motivados para a realização das mesmas, desse modo evitando exercícios em que os atletas aguardem muito tempo esperando por sua vez, assim, provocando uma maior motivação para a prática esportiva, uma vez que desde o primeiro contato com a modalidade esportiva, estará vivenciando as características do jogo propriamente dito mesmo que de forma reduzida.

Já a proposta metodológica do JDC (Jogos Desportivos Coletivos) se baseia em, segundo Leão e colaboradores (2011), o aprendizado dos esportes coletivos se dê pela sua compreensão. Iniciando o aprendizado através da tática para que posteriormente sejam realizadas atividades em forma de jogo, pois são os princípios dos mesmos que irão regular a atividades. Através dessas atividades a aprendizagem ocorrerá de forma gradativa, pois os treinadores e professores devem 
ficar atentos em manter os elementos principais do jogo formal, mesmo fazendo a utilização de jogos reduzidos.

Deve-se levar em consideração a escolha do jogo, sua complexidade deverá ser aumentada de forma gradativa conforme a evolução dos atletas e ou alunos, o professor deverá criar situações dentro do jogo de superioridade e inferioridade numérica e por fim, a dificuldade das atividades envolvendo tática, devem ser disponibilizadas de forma progressiva.

Lovatto e Gallati (2007) comentam que, quando os esportes coletivos são orientados de maneira compreensível, pode proporcionar um melhor desenvolvimento para seus praticantes no que diz respeito à inteligência e cooperação. A cooperação é de suma importância para obtenção do êxito da equipe (no caso do Basquete, uma maior pontuação para se conquistar a vitória). O JDC pode proporcionar um ambiente capaz de fazer com que os alunos e atletas praticantes, possam vivenciar as individualidades e principais características daquela modalidade esportiva coletiva que irá ser trabalhada.

Desde o primeiro momento, o método JDC se faz muito importante para que os alunos e atletas tenham não só o contato com a bola, mas também proporciona uma interação com os colegas de equipe diante de situações-problema, situações essas que devem ser ajustadas de acordo com o desenvolvimento dos alunos, levando em consideração as demandas da modalidade esportiva (no caso, o Basquetebol). Para Lovatto e Gallati (2007), os jogos (ou jogos adaptados) se mostraram ser mais interessantes por parte dos alunos, pois envolvem diversas situações condizentes com as características do jogo formal, mesmo que com regras adaptadas, número de jogadores e espaço reduzido.

No método de ensino Situacional, sabe-se que a sua utilização tem como base situações reais do jogo formal. Tal metodologia tem como objetivo desde o seu primeiro contato, desenvolver as capacidades táticas dos atletas sem dar uma maior importância para os fundamentos técnicos, pois tem como prioridade a resolução de problemas 
decorrentes do jogo, assim, dando ênfase a inteligência a criatividade dos atletas. As atividades propostas nessa abordagem metodológica tem o objetivo de estimular os alunos ou atletas a tomarem decisões mediante experiências que foram experimentadas anteriormente com igualdade, inferioridade e superioridade numérica de atletas.

Dallegrave e colaboradores (2017) buscaram apresentar a inclusão do método situacional nos treinos de uma equipe de Handebol. Inicialmente a equipe fazia a utilização do método analítico como proposta principal (exercícios realizados de forma isolada), durante 0 estudo foram realizadas 15 sessões de treino utilizando 0 método situacional. Foi constatado que os treinadores responsáveis pelo time, tiveram dificuldades em sua aplicação, pois segundo os mesmos, não possuíam a experiência necessária para sua utilização e os atletas não tiveram participação nas atividades de inferioridade ofensiva e superioridade defensiva.

Por outro lado, Pinho e colaboradores (2010) compararam a utilização do método Situacional e o método Misto (Global + Parcial) para averiguar os níveis de CTP (Conhecimento Tático Processual) em escolares entre 10-12 anos da modalidade Handebol. Foi constatado que o grupo em que foi feita à utilização do método Situacional obteve melhorias nos níveis de CTP em relação ao grupo que fez utilização do método Misto.

Esse resultado pode estar atribuído ao fato que os alunos do grupo que utilizava 0 método Situacional se mantinham mais motivados para a prática, já no grupo que utilizava o método Misto, se mostravam bastante desinteressados para prática, pois não gostavam da metodologia empregada, o que pode ter relação direta com os resultados que encontrados. 


\section{CONCLUSÃO}

Pode-se concluir que diante dos achados do presente trabalho, a utilização das metodologias de ensino irá depender do ambiente em que 0 treinador/professor estiver, seja na escola, na iniciação esportiva ou até mesmo no alto rendimento. $\mathrm{O}$ treinador ou professor deverá utilizar as abordagens metodológicas vistas no presente estudo de forma coerente, levando sempre em consideração as respostas advindas dos atletas/alunos, se foram às respostas esperadas e se, os objetivos esperados, com a utilização dos métodos de ensino escolhidos, estão de fato sendo alcançados. competência/experiência por parte do professor ou do treinador também é de suma importância para obtenção desses resultados.

\section{REFERÊNCIAS}

AMBRUST, M.; SILVA, A. L. A.; NAVARRO, A. C. Comparação entre método global e método parcial na modalidade futsal com relação ao fundamento passe. Revista Brasileira de Futsal e Futebol, São Paulo. Volume 2. Número 5. Páginas 77-81. Maio/Junho/Julho/Agosto. 2010.

BOLONHINI, S. Z.; PAES, R. R. A proposta pedagógica do Teaching Games for Understanding: reflexões sobre a iniciação esportiva. Pensar a Prática, volume 12, número 2, 2009.

CASAGRANDE, C. G. Ensino e aprendizagem dos esportes coletivos: análise dos métodos de ensino na cidade de Uberlândia-MG. 2012. 108 f. Dissertação (Mestrado em Educação Física) - Universidade Federal do Triângulo Mineiro, Uberaba, 2012.

COUTINHO, N. F.; SILVA, S. A. P. S. Conhecimento e Aplicação de Métodos de Ensino para os Jogos Esportivos Coletivos na Formação Profissional em Educação Física. Movimento, Porto Alegre, volume 15, número 01, páginas 117-144, janeiro/março de 2009.

COSTA, I. T.; GRECO, P. J.; MESQUITA, I.; GRAÇA, A.; GARGANTA, J. O Teaching Games for Understanding (TGfU) como modelo de ensino dos jogos desportivos coletivos. Revista Palestra, volume 10, páginas 69-77, 2010. 
DALLEGRAVE, E. J.; BERNO, C. S.; FOLLE, A. Método situacional: aplicação nos treinamentos técnico táticos de uma equipe de base do handebol feminino. Corpoconsciência, Cuiabá-MT, volume 21, número 01, páginas 100-113, Janeiro/Abril, 2017.

DAMASCENO, G. J.; TEIXEIRA, D. C. Métodos de treinamento empregado pelos treinadores nas escolinhas de futsal do município de Caratinga, MG e o desenvolvimento da inteligência tática. EFDeportes.com, Revista Digital, Buenos Aires - Año 16 - № 156 - Mayo de 2011.

GALATTI, R. L.; SERRANO, P.; SEOANE, A. M.; PAES, R. R. Pedagogia do esporte e basquetebol: aspectos metodológicos para o desenvolvimento motor e técnico do atleta em formação. Revista Arquivos em Movimento, Rio de Janeiro, volume 8, número 2, páginas 79-93, julho/dezembro, 2012.

JUNIOR, D. R. Esporte e atividade física na infância e na adolescência: uma abordagem multidisciplinar. Porto Alegre: Artmed, 2009.

LEÃO, I. C. S.; ALMEIDA, M. B.; SOUZA, F. T. C.; GRECO, P. J. Processos cognitivos e métodos de ensino em defesas abertas do Handebol. Neurobiologia, 74 (2), páginas 181-190, Abril/Junho, 2011.

LOVATTO, D. L.; GALATTI, L. R. Pedagogia do Esporte e dos Jogos Coletivos: das teorias gerais para a iniciação esportiva em Basquetebol. Movimento \& Percepção, Espírito Santo do Espinhal, SP, volume 8, número 11, Julho/Dezembro 2007.

MENEZES, R. P.; MARQUES, R. F. R.; NUNOMURA, M. Especialização esportiva precoce e o ensino dos jogos coletivos de invasão. Movimento, Porto Alegre, volume 20, número 01, páginas 351-373, janeiro/março de 2014.

MORALEZ, J. C. P.; SILVA, E. G.; MATIAS, C. J. A. S.; REIS, R. A.; GRECO, $P$. J. Processo de ensino-aprendizagem-treinamento no minibasquetebol. Fitness \& Performance Journal. 2009 setembro-outubro; 8(5):349-59. MORALEZ, J. C. P.; GRECO, P. J. A influência de diferentes metodologias de ensino-aprendizagem-treinamento no basquetebol sobre 0 nível de conhecimento tático processual. Revista brasileira de Educação Física e Esporte, São Paulo, volume 21, número 4, páginas 291-99, outubro/dezembro 2007. 
OLIVEIRA, J. E. C. Basquetebol. Aspectos históricos e funcionais. EFDeportes.com, Revista Digital. Buenos Aires, Año 17, № 174, Noviembre de 2012.

PINHO, S. T.; ALVES, D. M.; GRECO, P. J.; SCHILD, J. F. G. Método situacional e sua influência no conhecimento tático processual de escolares. Motriz, Rio Claro, volume 16, número 3, páginas 580-590, Julho/Setembro 2010.

RAMOS, V.; NASCIMENTO, J. V.; GRAÇA, A. Análise do processo de instrução no treino de jovens: um estudo de caso no basquetebol. Revista Portuguesa de Ciências do Desporto 9(1) 52-63.

ROMÃO, E. J. R.; BARBOSA, P. V. S.; MOREIRA, M. C. Metodologias de ensino para jogos esportivos coletivos na educação física escolar. Revista de Iniciação Científica da Universidade Vale do Rio Verde, Três Corações, volume 7, número 1, 2017, páginas 80-96.

SIPRIANO, M. J.; SEQUEIRA, P. Os meios de ensino/treino: do basquetebol de formação ao de alta competição. Revista Mackenzie de Educação Física e Esporte - Ano 7, número 2 , 2008.

TOLVES, B. C. F; DELEVATI, M. K.; SAWITZKI, R. L. Métodos Parcial, Global e de Jogos Condicionados no ensino do futsal. Revista Mackenzie de Educação Física e Esporte, São Paulo, volume 13, número 2, páginas 80-92, julho/dezembro 2014.

TUBINO, M. Estudos brasileiros sobre o esporte: ênfase no esporteeducação. Maringá: Eduem, 2010. 